\title{
To Assess the Knowledge of Blood Donation among Voluntary Blood Donor at Blood Bank, Krishna Hospital Karad (Maharashtra, India)
}

\section{Prabhuswami Hiremath*}

Krishna Hospital \& Medical Research Centre, Krishna Institute of Medical Sciences University, Maharashtra, India

\begin{abstract}
The theme of the 2012 World Blood Donor Day campaign, "Every blood donor is a hero" focuses on the idea that every one of us can become a hero by giving blood. Today, Blood Transfusion Services constitute a crucial part of any healthcare delivery system. Adequate and safe supply of blood and blood components is essential, to enable a wide range of critical care procedures to be carried out in hospitals. The objective of the present study was to identify the level of knowledge of blood donation among voluntary blood donors attending blood bank of Krishna Hospital Karad and to correlate the knowledge with sociodemographic variables. 100 voluntary Blood donors between the ages of 18 and 55 years were selected by Non probability Convenient Sampling technique. Descriptive Survey Design was employed for study. Structured knowledge questionnaire was given to assess their knowledge on Blood Donation. The study sample consisted of 64 males $(64 \%)$ and 36 females $(36 \%)$. The overall knowledge on blood donation among respondents was observed as good $10 \%$, average $56 \%$, and poor $34 \%$. In males the overall knowledge level was found good among $9 \%$, average $52 \%$ and poor $39 \%$. In females, good knowledge level was observed among $14 \%$, average $49 \%$, and poor $37 \%$. Education and gender was significantly associated with knowledge of blood donation where as education religion blood group and age were not statistically significant. In the present study researcher concluded that there is need for health education regarding blood donation, which will ultimately increases the awareness among general population to motivate for voluntary blood donation.
\end{abstract}

Keywords: Tobacco; Blood donation; Knowledge

\section{Introduction}

Today, Blood Transfusion Services constitute a crucial part of any healthcare delivery system. Adequate and safe supply of blood and blood components is essential, to enable a wide range of critical care procedures to be carried out in hospitals. India with a population of about one hundred and twenty crore is naturally the country which requires lot of blood to save lives of citizens. It has been quoted that there is need of 8 million units of blood every year in our country. Out of this, only half that is around 4 million units of blood can be obtained from voluntary blood donors. Rest all comes from replacement blood donation from relatives or paid donors. On 14 June, countries worldwide celebrate World Blood Donor Day with events to raise awareness of the need for safe blood and blood products and to thank voluntary unpaid blood donors for their life-saving gifts of blood. The theme of the 2012 World Blood Donor Day campaign, "Every blood donor is a hero" focuses on the idea that every one of us can become a hero by giving blood. While recognizing the silent and unsung heroes who save lives every day through their blood donations, the theme also strongly encourages more people all over the world to donate blood voluntarily and regularly. Transfusion of blood and blood products saves millions of lives each year. In the most developing countries, however, preventable deaths still occur due to inadequate supply of safe blood and blood products. Most of this burden falls on women and children as a consequence of pregnancy-related complications, malnutrition, malaria and other infectious diseases. Trauma, including road traffic accidents and injuries due to armed conflicts increase the demand for blood. Despite its vital role in saving life, blood transfusion may expose the recipient to a number of adverse effects which can be life-threatening. These include the transmission of infections such as HIV/AIDS, hepatitis B and hepatitis C which are of immense public health importance due to their high prevalence in the African Region. The objective of the present study was to identify the level of knowledge of blood donation among voluntary blood donors attending blood bank of Krishna Hospital Karad and to correlate the knowledge with sociodemographic variables.

\section{Material and Methods}

This study was carried out in a Krishna Hospitals Blood Bank, Karad. The Blood Bank recognized and registered as a Regional Blood Transfusion Center under State Blood Transfusion Council of Maharashtra. Hundred voluntary Blood donors between the ages of 18 and 55 years were selected by Non probability Convenient Sampling technique. Non experimental Descriptive Survey Design was employed for study. Samples those who are present at the time of data collection, who know Marathi, Hindi \& English language and both sex were include in study. Those who are not willing to participate were excluded from the study. Informed consent was obtained from the samples then knowledge questionnaire was given to assess their knowledge on Blood Donation. Data was analyzed with descriptive statistics (frequency, percentage, mean \& standard deviation) and inferential statistics (chi square $\left(\mathrm{X}^{2}\right)$ ) is used to determine the association between selected demographic variables and knowledge of blood donor.

\section{Results}

The response was gathered from a total of 100 respondents voluntarily participated in the survey. The study sample consisted of 64 males (64\%) and 36 females (36\%). The mean age of male donors was 30 years and the mean age of female students was 26 years.

Among 100 donors, 49\% have donated blood only once and 51\% donated blood whenever there is a need. Majority $(67 \%)$ of donors

*Corresponding author: Prabhuswami Hiremath, Krishna Hospital \& Medica Research Centre, Krishna Institute of Medical Sciences University, Maharashtra, India, E-mail: prabhu252003@yahoo.co.in

Received December 07, 2012; Accepted December 26, 2012; Published December 31, 2012

Citation: Hiremath P (2012) To Assess the Knowledge of Blood Donation among Voluntary Blood Donor at Blood Bank, Krishna Hospital Karad (Maharashtra, India). J Nurs Care 1:124. doi:10.4172/2167-1168.1000124

Copyright: (c) 2012 Hiremath P. This is an open-access article distributed unde the terms of the Creative Commons Attribution License, which permits unrestricted use, distribution, and reproduction in any medium, provided the original author and source are credited. 
among respondents donated blood voluntarily, 30\% had donated blood only for relatives or friends. A total of 33 (33\%) men and 21 (21\%) women had donated blood at least once in the past.

Knowledge of blood donation among donors was measured by using 50 questions. The overall knowledge on blood donation among respondents was observed as good $10 \%$, average $56 \%$, and poor $34 \%$. In males the overall knowledge level was found good among $9 \%$, average $52 \%$ and poor $39 \%$. In females, good knowledge level was observed among $14 \%$, average $49 \%$, and poor $37 \%$. Education and gender was significantly associated with knowledge of blood donation where as education religion blood group and age were not statistically significant.

\section{Discussion}

The population-based cross-sectional study was conducted at Gangtok in the state of Sikkim, India, on 300 subjects to analyze the factors of knowledge of prospective blood donors that may influence their perception and awareness about blood donation. They found that $46 \%$ of the study populations have high knowledge score. The knowledge about blood donation was found to be statistically significant with the occupational status and the education levels [1].

A Descriptive cross sectional study was conducted at Northern Nigeria to determine the knowledge and blood donation practices among adults. A result shows that the knowledge of the respondents on blood donation was low. Less than half $46.2 \%$ knew some indications for blood transfusion. $22.6 \%$ respondents had donated blood in the past but only $1 \%$ of these were VBD while $95 \%$ were donations based on blood needs by family members, relations and friends. Few respondents $12 \%$ had received blood transfusion in the past, and the main source of blood transfused was paid commercial donors $44.6 \%$. The fear of HIV screening was a major hindrance and limitation to voluntary blood donation among respondents. They suggested that gaps in knowledge \& practice of VBD can be addressed through public awareness campaigns, and motivational programmes such as free medical services for voluntary blood donors [2].

Okpara [3] also recommended in his study that more positive steps should be taken to educate the population about blood donation and transfusion because the most common reason for non-donation and non-acceptance of blood transfusion is religious belief.
Many of review reported that have reported fear of complications, fear of hospitals, lack of knowledge \& awareness, false beliefs and religious traditions as the main reasons for not donating blood [4-6].

Mousavi et al. [7] assessed the knowledge of Iranian population on blood donation and found mean knowledge score of 8 which is highly significant with Age, gender and level of education.

\section{Conclusion}

The knowledge on blood donation can affect one's willingness to donate blood and ultimately, this could help improve the number of blood donors. The study will help to know the factors contributing to decrease in number of young blood donors, which is vital in formulation of effective interventions. In the present study also researcher concluded that there is need for health education in the fields of blood donation, which will ultimately increases the awareness by increase in advertisements and use of media among general population to motivate for voluntary blood donation.

\section{References}

1. Shenga N, Pal R, Sengupta S (2008) Behavior disparities towards blood donation in Sikkim, India. Asian J Transfus Sci 2: 56-60.

2. Salaudeen AG, Musa OI, Awoyemi AO, Bolarinwa AO, Adegboye AO, et al. (2011) Community survey on blood donation practices in a northern state of Nigeria. J Prev Med Hyg 52: 21-25.

3. Okpara RA (1989) Attitudes of Nigerians towards blood donation and blood transfusion. Trop Geogr Med 41: 89-93.

4. Hosain GM, Anisuzzaman M, Begum A (1997) Knowledge and attitude towards voluntary blood donation among Dhaka University students in Bangladesh. East Afr Med J 74: 549-553.

5. Wiwanitkit $\mathrm{V}(2000)$ A study on attitude towards blood donation among people in a rural district, Thailand. Southeast Asian J Trop Med Public Health 31: 609611.

6. Boulware LE, Ratner LE, Ness PM, Cooper LA, Campbell-Lee S, et al. (2002) The contribution of sociodemographic, medical, and attitudinal factors to blood donation among the general public. Transfusion 42: 669-678.

7. Mousavi F, Tavabi AA, Golestan B, Ammar-Saeedi E, Kashani H, et al. (2011) Knowledge, attitude and practice towards blood donation in Iranian population. Transfus Med 21: 308-317. 